\title{
A Simplified Method to Determine the Potential Growth in Orthodontics Patients
}

\author{
Gladia Toledo Mayarí \\ School of Dentistry/ Havana Medical University \\ Cuba
}

\section{Introduction}

The current Orthodontics worries is about the early correction of malocclusion, giving importance to the harmonization of the bone bases in connection with the discrepancy and positioning of the teeth, that can be corrected in any time of life, for what is of great importance is to know the biggest peak of growth (Peluffo, 2001; Quirós 2000).

The maturation stages can have a considerable influence in the diagnosis, the goals of the treatment, the planning and the eventual result of the orthodontic treatment (Madhu et al., 2003; Toledo 2004).

The clinical decisions with regards to the use of the extraoral force, functional appliances, the treatment without extractions and the orthognatic surgeon is based on the considerations of the growth, for this reason, the prediction of the quantity of active growth, mainly in the craniofacial complex, are useful to the orthodontists (Toledo, 2004).

The orthodontic diagnosis has a group of stages in those that have multiple evaluation factors which are used in the study of the malocclusions. In general evaluation of a patient, it is important to consider the general physical development and the potential growth (Quirós 2000).

The pubertal growth spurt of is an advantageous period in the orthodontic treatment and it should be kept in mind in connection with the planning of the treatment. One of the objectives of the orthodontic treatment during the adolescence, in the cases with skeletal discrepancies is to take advantage of the changes of growth of the patient. (Fiani, 1998; Padrós \& Creus, 2002).

In the adolescent, the phase of somatic maturity can influence in the selection of the appliances, the course of the treatment and the retention after the therapy (Geran et al. 2006). Because of this the study and the knowledge of the maturation stage and the phase of growth of the patient, is very important for making more efficient therapy. Authors like Nanda (Nanda, 1955), Björk and Helm (Björk \& Helm, 1967), and Hägg and Taranger (Hägg \& Taranger, 1980a, 1980b, 1982) established that the pattern of growth and facial development is similar to that of the general skeletal growth, and that the maximum peak of pubertal growth of the craniofacial structures occurs between 6 and 8 months after the maximum peak of pubertal growth in the stature. 
Due to the wide individual variation, the chronological age cannot be used in the evaluation of the pubertal growth (Fiani, 1998), for that reason is appealed to determine the biological age. It is calculated starting from the bone, dental, morphological and sexual ages (Ceglia, 2005).

The study of the bone maturation is the surest and reliable method to evaluate the biological age of the individuals and to fix the physiologic maturity (Gutiérrez Muñiz et al. 2006).

In spite of the difficulties that outline the different existent methods (quality of the X-ray, minimum modifications of the projection, variability intra and inter observant, errors in the reading of the online systems, population in which the method is based, etc.) the evaluation of the bone maturation is indispensable in the clinical practice, since it is a parameter of great importance in the study of the alterations of the growth (Paesano et al, 1998).

The hand, the wrist and the distal epiphysis of the radius and the ulna present a great number of secondary centers of ossification on the whole, and they can reproduce in a single $X$-ray. For this reason, they are often chosen as study centers when it is sought to determine the state of skeletal maturation, although other centers of ossification of secondary epiphysis can be used, such as, the elbow and the tarsal bones (Cha, 2003).

Todd, in 1937, was the first author that mentioned the term "determinant of the maturity", when referring to the gradual changes that occur on the growth of the cartilage during the trial of coalition of the epiphysis with the diaphysis and that they can be determined by studying radiographic plaques (Quirós Álvarez, 2006). Years later Greulich and Pyle called them indicators of maturity and in 1959 they established the norms of skeletal age to value the bone maturation of the complete hand (Greulich \& Pyle, 1959). As the different epiphyses don't often mature at the same time, discrepancies that are resolved with subjective trials which subtract precision to the method arise (Tanner et al. 1983).

Tanner and Whitehouse (Tanner et al. 1983), develop the method Tanner - Whitehouse 2 (TW2) to evaluate the bone development, through X-rays of the lefts hand and wrist, which has had great acceptance for their precision, being used at the present time in numerous countries (Izaguirre de Espinoza et al. 2003; Jiménez Hernández et al., 1986; Ortega et al., 2006).

In 1979, the professor Jordan (Jordan, 1979) publishes the results of the Study of Physical Growth in Cuba, where it uses the method TW2 in the determination of the bone maturation. Later on, in 1987 a group of investigators of the Department of Growth and Human Development determine the patterns of the Cuban population's bone maturation for sex and race through the method TW2 (Jiménez JM et al., 1987). This method is one of those that is used in Cuba in the evaluation of the bone maturation (Abreu Suárez et al., 1995).

Some authors have looked in the X-rays of the hand specific indicators of the spurt of pubertal growth (Fishman, 1982). Björk and Helm (Björk \& Helm, 1967) and Gupta (Gupta, 1995) point out as a reliable indicator of the installation of the puberty, the beginning of the ossification of the sesamoid bone. Toledo (Toledo, 2004) and Rakosi and Jonas (Rakosi \& Jonas, 1992) affirm that the appearance of the hook of the hamate bone is also a good indicator of the installation of the puberty. 
In Maxillary Orthopedics one of the most utilized methods in the evaluation of the growth potential has been the one of Grave and Brown (Rakosi \& Jonas, 1992; Tedaldi et al., 2007) that it divides the process of maturation of the bones of the hand in nine stages, between the 9 th and the 17th year of age. The ossification characteristics are detected to the level of the phalanges, bones of the carpus and radius, and the stages of growth of the fingers are valued according to the relationship between the epiphysis and the diaphysis (Fiani, 1998). The evaluation of the Grave and Brown's method is recommended by Ortiz et al. (Ortiz et al., 2007), Spinelli Casanova et al. (Spinelli Casanova et al, 2006) and Pancherz and Hägg (Pancherz \& Hägg, 1985) before the therapeutic interceptive in Orthodontics patients, to choose the ideal treatment according to the stages of bone maturation that the patient presents, diminishing this way the time in the use of the appliances and making them more effective. Previous to the realization of this investigation (Toledo Mayarí \& Otaño Lugo, 2010a, 2010b, 2010c), was not reported in Cuba the use of Grave and Brown's method.

The inconvenience that presents the evaluation of the bone maturation through the hand in orthodontics patients, is the use of an additional X-ray for the patient, besides that this is not carried out with the dental X-ray machine, being necessary to remit the patient to a radiology service.

The current tendency in Orthodontics is to reduce the number of X-rays to the strictly necessary ones (Bujaldón Daza et al., 1998), for that indexes of skeletal maturation have been developed with the profiles of the bodies of the cervical vertebras that generally appear in the lateral teleradiography of skull used for the orthodontist diagnostic (Ortiz et al., 2007), being discharges correlations in the evaluations of the bone age between the cervical vertebras and the bones of the hand (Edilmar et al., 2005; Gandini et al., 2006; Hassel \& Farman, 1995; San Roman et al., 2002; Uysal et al., 2006).

Also with the objective of substituting the X-ray of the hand that constitutes an additional exhibition to radiations in the patients of Orthodontics, Leite et al. (Leite et al., 1987), analyze the first three fingers, which include in the lateral teleradiography of skull and they don't find significant differences between the analysis of the bone maturation of the total hand and that of the three fingers. Shigemi Goto et al. (Shigemi Goto et al., 1996) and Rossi et al. (Rossi et al., 1999), analyze the changes at level of the first finger, in the distal phalanx and in the proximal respectively, finding that the evaluations at level of the phalanges constitute a quick and useful clinical method, to evaluate the growth potential in patient of Orthodontics. Madhu et al. (Madhu et al., 2003) and Ozer et al.((Ozer et al., 2006) use the stages of maturation of the middle phalange of the third finger, visualized in an X-ray of $41 \times 31 \mathrm{~mm}$., taken with a machine of dental $\mathrm{X}$ rays conventional, where they find out that the evaluation of the stages of maturation of the middle phalanx of the third finger, constitutes an alternative method that can be used to determine the bone maturation, of the children in growth. Previous to the realization of this investigation, was not reports that in Cuba the patient's growth potential was evaluated through the middle phalange of the third finger, that which motivated us to determine the stages of maturation of that phalange and to identify the concordance between these and the stages of skeletal maturation, whereas clause that of existing concordance among the same ones, we will have a simplified method, for the determination of the growth potential, without the necessity of using an X-ray of the hand and an additional X-rays machine. 
Problem of Investigation:

Whereas clause that in Orthodontics the evaluation of the growth potential has influence in the diagnosis, the treatment plan, the results and the prognostic of the treatment, and that the evaluation of the bone maturation through the X-ray of the hand, that is the anatomical area that is used in the evaluation of the bone maturation in Cuba, constitutes an additional X-ray for the tributary patients of orthodontist treatment, it would be necessary to respond:

What is the bone age of our patients?

What stages of skeletal maturation and of maturation of the middle phalange of the third finger they do present the same ones?

What is the relationship between the bone age and the chronological age, the stages of skeletal maturation and the stages of maturation of the middle phalange of the third finger in our patients?

What concordance does it exist among the methods to determine the growth potential in patient of Orthodontics?

The formulation of these questions forms the bases of a hypothesis that can be defined as it continues:

Considering that the growth potential constitutes the grade of growth becomes for the individual between the state in the moment of the exam and the definitive ceasing of this. In the determination of this potential, inside the diagnosis in Orthodontics, you can substitute the radiographic of the hand, being clinically useful the analysis of the bone maturation through the middle phalange of the third finger.

To give answers to the questions and the hypothesis, the following objectives were formulated:

General objective: To propose a simplified method to determine the growth potential in Orthodontics patient.

Specific objectives:

1. To determine according to sex and chronological age: the bone age, the stages of skeletal maturation and the stages of maturation of the middle phalange of the third finger.

2. To identify the relationship between the bone age and: the chronological age, the stages of skeletal maturation and the stages of maturation of the middle phalange of the third finger.

3. To identify the concordance between the studied methods.

\section{Background}

In this epigraph are approached theoretical aspects of great importance in the specialty of Orthodontics that were considered in this investigation, due to the great majority of the children that go to the clinic and they are tributary of orthodontic treatment, they are in periods of growth and development, reason why when ignoring their biological age, we could incur in errors when outlining a diagnosis, prognostic and treatment plan. 
The terms of growth and development are used to indicate the series of changes of volume, forms and weight that suffers the organism from the fecundation until the mature age (Cannut Brusola, 1988; J. Mayoral \& G. Mayoral, 1990).

The growth in an individual's active development, is a continuous phenomenon that begins in the moment of the conception and it culminates at the end of the puberty, period during which reaches the maturity in their physical, psycho-social and reproductive aspects. Both processes have characteristic communes to all the individuals of the same species, what makes them predictable, however, they present wide differences between the subjects, given by the pattern's of growth individual character and development. This typical pattern emerges on one hand of the interaction of genetic and environmental factors that establish the growth potential and for other, the magnitude that this potential is expressed (Proffit, 1994).

The chronological age, that constitutes the time lapsed from the birth until the moment of the exam (Proffit, 1994), it doesn't always allow to value the development and the patient's somatic maturation, for that is appear to determine the biological maturity (Fiani, 1998).

According to Gutiérrez Muñiz et al. (Gutiérrez Muñiz et al., 2006) "the concept of biological maturity is defined as the successive transformations through the time, from the conception until the adulthood, existing two applicable fundamental methods at the present time for its evaluation: the bone age and the dental age".

The bone age is established determining radiograph of the number and size of the centers of ossification epiphysis, which should be compared with the existent norms for each age and sex (Recalde Cortes et al. 1997; Tanner et al., 1983). Each bone begins with a primary center of ossification that will grow progressively at the same time that is remodeled being able to acquire an or more epiphysis and finally it will acquire the mature form with the coalition from the epiphysis to the body of the bone. The sequence for each bone is the same as for the events that will happen in it, taking place independently late to the grade or advance with regard to the chronological age (Cattani, 2003; Fiani, 1998; Proffit, 1994).

The potential growth constitutes the grade of growth becomes for the individual between the state in the moment of the exam and the definitive ceasing of this (Proffit, 1994). It is given by the existent relationship between the bone age and the chronological age: to smaller bone age for a certain chronological age the individual's growth potential will be bigger, that is to say, the grade late of the bone age in connection with the chronological age reflects theoretically the years of growth residual extra or, that is the same thing, the years of growth that he has left before the closing of the epiphysis (Cattani, 2003; Proffit, 1994).

Theoretically, any part of the body can be used to determine the bone age, but in practice the hand and the wrist, are the most used, because they possess a great number of bones and epiphyses in development what allows the pursuit of the changes that happen through the years of the growth (Freitas et al. 2004; Jordan, 1979). They are also the most convenient areas to value the bone maturation, to be far from the gonads and to need less radiation (Jordán et al. 1987; Recalde Cortes et al. 1997).

The methods that are used to evaluate the growth potential of the left hand are: the TW2 that determines the bone age according to the maturation stages of each one of the bones; and the Grave and Brown that divides the process of maturation of the bones in nine stages 
of skeletal maturation. These two methods have disadvantage for the Orthodontics patients because the use of an additional X-ray, which is not carried out in the dental $\mathrm{X}$ rays machine, being necessary the patient's remission.

The current tendency in Orthodontics in the evaluation of the bone maturation is to reduce the number of X-rays to the strictly necessary ones (Bujaldón Daza et al., 1998), for that investigators exist as: Hassel and Farman (Hassel \& Farman, 1995) that they try to develop some indexes of skeletal maturation with the profiles of the bodies of the cervical vertebras that appear in the lateral teleradiography of skull used for the orthodontist diagnostic. The advantages of using the cervical vertebras, it is centered in the reduction of radiographies to those that are subjected to the patients and for the easiness of consenting to the same ones (Ortiz et al., 2007).

Also in patient of Orthodontics with the objective of doing without of the X-ray of the hand that constitutes an additional exhibition to radiations, and it implies the use of a machine of rays $X$ that is not used in a conventional way in Dentistry; the evaluation of the bone maturation has been used and of the growth potential through the development of the phalanges, that also has the purpose of simplifying the estimate, since alone the changes are analyzed at level of some phalanges, according to the relationship between the epiphysis and the diaphysis (Madhu et al., 2003).

Inside the diagnosis in Orthodontics, it is very important the evaluation of the growth potential, since most of the patients that require orthodontist treatment, are in a period of active growth, and with the treatment it can modify the facial growth, well be braking it, accelerating it or forward a normal vector (Tedaldi et al, 2007). According to Proffit (Proffit, 1994) it is not possible to modify a growth that is not taking place, and if a functional apparatus is placed on a patient that is not growing, the obtained result will be almost totally a dental mobilization.

The children with maxillary discrepancies usually benefit from the application of techniques to modify the growth. Since the bones of the face, and in particular the maxillary ones, suffer spontaneous changes during the different phases of growth, before establishing a treatment to correct skeletal malocclusions, it is necessary to know the opportune moment to begin the same one, according to the growth potential that the patient presents, to make more efficient our therapy (Tedaldi et al., 2007, Proffit, 1994).

The guiding principle is that growth can only be modified when it is occurring (Proffit, 1994), there is the importance of knowing the growth potential that the patient presents, when we carry out the diagnosis of the skeletal problems. Keeping in mind these aspects motivates ourselves to determine in the same sample three appraisal methods of the growth potential (Method TW2, Serious method and Brown, and determination of the stages of maturation of the half phalange of the third finger), with the objective of to propose a simplified method to determine the growth potential in patient of Orthodontics.

\section{Methodological design}

A cross-sectional technological innovation research was conducted in the period of January 2004 to April 2007, in the Clinic of Orthodontics of Havana School of Dentistry, in a sample of 150 patients between 8 and 16 years of age. A sampling was used by quotas 
according to sex and age, being divided in two groups, 75 for each sex. The patients were selected with previous condition to present good state of general health; to have measures of weight and height, that were between 10 and 90 percentile, of the Cuban Score of Weight for Height (Gutiérrez Muñiz et al., 2006); absence of chronic illnesses; absence of oligodontias; absences of congenital malformations; that they didn't have treatment corrective of the spinal column ; the need for the characteristics of their malocclusion, the realization of a lateral teleradiography of skull to complete their diagnosis; and to have signed the informed consent in writing.

\subsection{Variables}

Were studied the variables: chronological age, bone age (TW2), sex, stages of skeletal maturation and stages of maturation of the middle phalanx of the third finger.

Chronological age: Was considered the decimal age (Jordán, 1979): For the calculation, we subtracted the boy's date of birth and the date of the exam. The numeral was provided by the last two digits of the year and the decimal fraction was looked for in the table of decimal age.

Bone age (TW2): Was calculated in dependence of the sum of the punctuation of each stage for Radius, Ulna and Fingers, according to the patterns of the Cuban population's bone maturation, for the method TW2 (Jiménez et al., 1987).

Sex: Female and male.

Stages of skeletal maturation: Was classified according to Grave and Brown's method in stages of the 1 at 9 .

Stages of maturation of the middle phalanx of the third finger: Was classified according to the relationship among the epiphysis and the diaphysis in one of the following stages (Toledo, 2004):

a. The epiphysis has smaller width than the diaphysis.

b. The epiphysis has the same width with the diaphysis.

c. The epiphysis surrounds the diaphysis by way of cap.

d. Begins the coalition between the epiphysis and the diaphysis.

e. Where the epiphysis becomes ossified with the diaphysis.

\subsection{Ethical aspects}

With all the patients that participated in the investigation and their parents, an interview was conducted before the beginning of that, where they were explained on what it consisted with the study, frequency, evaluation type and the radiological protection measures that would be taken for not damaging the patient's health. If they agreed, the patients and their parents should sign the informed consent, approving their holding in the study.

\subsection{Technical and procedures of obtaining the information}

\subsubsection{For the determination of: The bone age and the stages of skeletal maturation}

Firstly you proceeded to each observer's training in the appraisal methods of the studied maturation. The information was picked up and analyzed by two residents and two 
specialists of Orthodontics, each resident and each specialist determined in the same sample, one of the two methods of study of the maturation analyzed in this investigation (method TW2 and method of Grave and Brown).

To each patient was made the clinical history of Orthodontics and was realized an radiographic of the left hand (Fig. 1) where they were determined: the bone age for the method TW2 (Jiménez et al, 1987) and the stages of skeletal maturation for the method of Grave and Brown (Tedaldi et al. 2007).

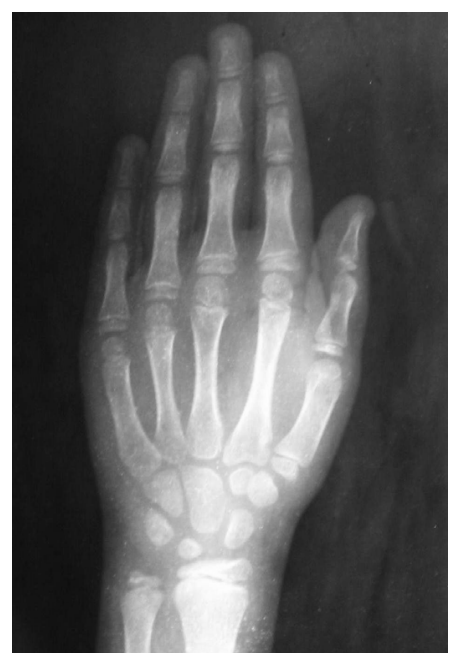

Fig. 1. Radiographic of the left hand.

The radiographic of the left hand was realized with the same regulations that the utilized ones in the National Study of Growth and Human Development in Cuba, carried out by Jordan (Jordán, 1979).

Each radiographic of the left hand was evaluated by the resident and the specialist in a first observation and in three weeks later in a second observation; that is to say a total of four times to calculate the variability inter and intra observant. The cases where discrepancy existed they were studied again to obtain the final results.

\subsubsection{To determine the stages of skeletal maturation of the middle phalanx of the third finger of the left hand}

In a paper of size Letter $(21,59 \mathrm{~cm}$. x 27,94 cm.), at a distance of $10 \mathrm{~cm}$. of the superior margin and $10 \mathrm{~cm}$. of the left margin, the contour of a film dental standard, Kodak marks, of 41x31 $\mathrm{mm}$. was traced, and it was clipped by the traced area, being an opening in the paper with the dimensions of the dental film.

The paper was placed on the X-rays of the left hand of the 150 studied patients, it was made coincide the opening of the paper on the union between the middle phalanx and the proximal phalanx of the third finger and it was placed on a fixed negatoscope (Fig. 2). 


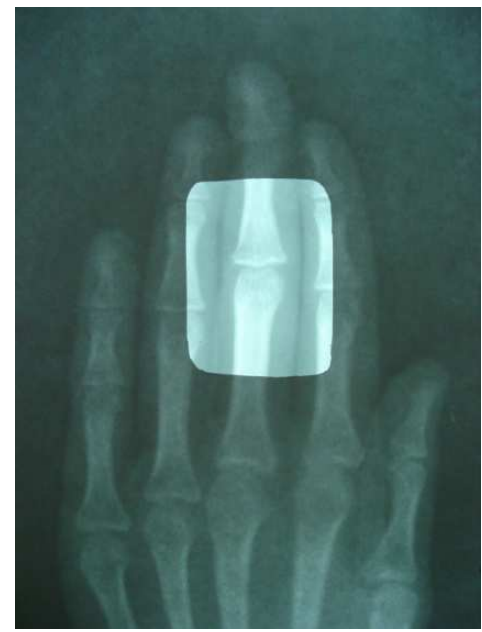

Fig. 2. Placement of the prepared paper on the union between the middle phalanx and the proximal phalanx of the third finger, in the radiographic of the left hand.

The analysis of the radiographic was carried out using a compass to measure the bone size in the middle phalanx and the maturation stage was classified with A to E, according to the classification proposed by Toledo (Toledo, 2004). With this procedure it was possible to locate each patient evaluated in a stage of maturation of the middle phalanx of the third finger, the same one was carried out by the main investigator and a specialist in Orthodontics, member of the investigation team, in two different opportunities to calculate the variability intra and inter observant.

\subsection{Technical and procedures of elaboration and analysis}

The information was stored in a data base automated in the system Excel, of the package Office 2003 on Windows XP professional and for the prosecution of the results the statistical packages SPSS version 11.5 and STATISTICA version 6.1 were used.

To calculate the variability intra and inter observant in the studied methods, the coefficient Kappa was applied (Begole, 2003).

The percentage was used for the qualitative variables and for the quantitative variables the arithmetic mean like measure summary and the standard deviation like variation measure (Bayarre et al. 2005).

You prove statistics employees: The association grade was calculated among the quantitative variables by means of the lineal correlation coefficient of Pearson (Begole, 2003) and the association grade among the variables in ordinal scales by means of the correlation coefficient of ranges of Spearman (Begole, 2003). To calculate the concordance among the results obtained in the studied methods, the coefficient Kappa was applied (Begole, 2003).

In all the used statistical tests, the used level of significance was of 0.05 .

The results were presented in tables designed to the effect. 


\section{Results}

In this epigraph the main results are presented, it contains the analysis of 6 tables.

The analysis of the variability intra and inter observant, their agreement was evaluated regarding the methods studied by means of an index Kappa. With relationship to the variability intra observant, that is to say, the level of discrepancy with regard to the valuations of oneself after three weeks, discrepancies didn't exist, in the three valued methods, being the agreement of 1,000 in the 150 cases, in each one of the methods. With relationship to the variability inter observant, that is to say, the level of discrepancy with regard to the valuations among the two observants, discrepancies didn't exist among these, being the agreement of 1,000 in the 150 cases, for these three methods.

\subsection{Determination according to sex and chronological age of: The bone age, the} stages of skeletal maturation and the stages of maturation of the middle phalanx of the third finger

\subsection{Identification of the relationship among the bone age and: The chronological age, the stages of skeletal maturation and the stages of maturation of the middle phalanx of the third finger}

Table 1 shows the arithmetic mean and the standard deviation of the chronological age and the bone age, calculated by the method TW2, according to groups of ages in the feminine sex, were found that in the groups of ages that were between the 8,00 and the 12,99 years and of 15.00 to 16.99 years, the bone age was bigger than the chronological one, being smaller in the remaining groups of ages. The coefficient of lineal correlation of Pearson among the bone age (TW2) and the chronological one presented a value of 0,977 ; that which signifies a very strong positive correlation, highly significant $(\mathrm{p}<0,010)$.

\begin{tabular}{|c|c|c|c|c|}
\hline \multirow{2}{*}{ Group of Ages } & \multicolumn{2}{|c|}{ Chronological age } & \multicolumn{2}{c|}{ Bone age (TW2) } \\
\cline { 2 - 5 } & $\mathrm{X}_{1}$ & $\mathrm{DE}_{1}$ & $\mathrm{X}_{2}$ & $\mathrm{DE}_{2}$ \\
\hline $8,00-8,99$ & 8,38 & 0,33 & 8,72 & 1,22 \\
\hline $9,00-9,99$ & 9,87 & 0,17 & 10,55 & 0,47 \\
\hline $10,00-10,99$ & 10,53 & 0,33 & 10,58 & 0,98 \\
\hline $11,00-11,99$ & 11,58 & 0,24 & 12,36 & 0,47 \\
\hline $12,00-12,99$ & 12,75 & 0,20 & 13,32 & 0,89 \\
\hline $13,00-13,99$ & 13,42 & 0,28 & 12,57 & 0,73 \\
\hline $14,00-14,99$ & 14,86 & 0,01 & 14,78 & 0,46 \\
\hline $15,00-16,99$ & 15,19 & 0,14 & 15,20 & 0,70 \\
\hline
\end{tabular}

$\mathrm{r}=0,977 \mathrm{p}=0,000 \mathrm{n}=75$

$\mathrm{r}$ (lineal correlation coefficient of Pearson among bone age (TW2) and chronological age).

Table 1. Arithmetic mean (X) and standard deviation (DE) of chronological age and bone age (TW2) by groups of age in females. 
Table 2 shows the arithmetic mean and the standard deviation of the chronological age and the bone age calculated by the method TW2 according to groups of ages in the masculine sex, it was found that in the groups of ages that were between 8,00 and 12,99 years, the bone age was smaller than the chronological one, being bigger starting from 13,00 years. The coefficient of lineal correlation of Pearson among the bone age (TW2) and the chronological one presented a value of 0,983 ; that which signifies a very strong positive correlation, highly significant $(p<0,010)$.

\begin{tabular}{|c|c|c|c|c|}
\hline \multirow{2}{*}{ Group of Ages } & \multicolumn{2}{|c|}{ Chronological age } & \multicolumn{2}{c|}{ Bone age (TW2) } \\
\cline { 2 - 5 } & $\mathrm{X}_{1}$ & $\mathrm{DE}_{1}$ & $\mathrm{X}_{2}$ & $\mathrm{DE}_{2}$ \\
\hline $8,00-9,99$ & 8,98 & 0,66 & 8,94 & 0,97 \\
\hline $10,00-10,99$ & 10,83 & 0,03 & 9,96 & 0,87 \\
\hline $11,00-11,99$ & 11,40 & 0,35 & 11,35 & 0,92 \\
\hline $12,00-12,99$ & 12,66 & 0,35 & 12,36 & 0,94 \\
\hline $13,00-13,99$ & 13,44 & 0,20 & 14,24 & 0,47 \\
\hline $14,00-14,99$ & 14,52 & 0,20 & 14,83 & 0,37 \\
\hline $15,00-15,99$ & 15,55 & 0,20 & 15,61 & 0,48 \\
\hline $16,00-16,99$ & 16,40 & 0,20 & 16,46 & 0,61 \\
\hline
\end{tabular}

$\mathrm{r}=0,983 \mathrm{p}=0,000 \mathrm{n}=75$

$\mathrm{r}$ (lineal correlation coefficient of Pearson among bone age (TW2) and chronological age).

Table 2. Arithmetic mean (X) and standard deviation (DE) of chronological age and bone age (TW2) by groups of age in males.

Table 3 shows the arithmetic mean and the standard deviation of the chronological age and the bone age (TW2) according to stages of skeletal maturation and sex, it was found that in each maturation stage, the averages of the chronological age were smaller in the feminine sex than in the masculine one. With relationship to the bone age calculated by the method TW2, in the feminine sex the averages of the same one went superior to those of the chronological age, in all the studied stages, however, in the masculine sex the bone age overcame the chronological one in the stages $4,5,6$ and 8 . The stages 4 and 5 are those of more clinical significance, belonged together with the chronological ages of 11,35 and 11,77 years in the feminine sex and 13,76 and 13,82 years in the masculine one and with the bone ages of 11,78 and 12,34 years in the feminine sex and of 14,20 and 14,57 years in the masculine one. It was observed that the females were earlier in their maturation stages than the males and that the stages advanced as it increased the chronological age and the bone age of the patients, in both sexes. The coefficient of correlation of ranges of Spearman among the bone age (TW2) and the stages of skeletal maturation presented a value of 0,855 in the feminine sex and 0,903 in the masculine one, both sexes showed a positive correlation, very significant $(p<0,010)$. In the studied sample they were not patient in the stage 9 . 


\begin{tabular}{|c|c|c|c|c|c|c|c|c|}
\hline \multirow{2}{*}{$\begin{array}{l}\text { Stages of skeletal } \\
\text { maturation }\end{array}$} & \multicolumn{4}{|c|}{ Chronological age } & \multicolumn{4}{c|}{ Bone age (TW2) } \\
\cline { 2 - 9 } & \multicolumn{2}{|c|}{ Female } & \multicolumn{2}{|c|}{ Male } & \multicolumn{2}{c|}{ Female } & \multicolumn{2}{c|}{ Male } \\
\cline { 2 - 9 } & $\mathrm{X}_{1}$ & $\mathrm{DE}_{1}$ & $\mathrm{X}_{1}$ & $\mathrm{DE}_{1}$ & $\mathrm{X}_{2}$ & $\mathrm{DE}_{2}$ & $\mathrm{X}_{2}$ & $\mathrm{DE}_{2}$ \\
\hline 1 & 8,59 & 0,66 & 11,38 & 1,34 & 8,97 & 1,25 & 10,66 & 1,11 \\
\hline 2 & 10,06 & 0,54 & 11,61 & 0,87 & 10,25 & 0,71 & 10,50 & 1,20 \\
\hline 3 & 11,63 & 1,35 & 11,71 & 0,65 & 11,82 & 0,84 & 10,50 & 0,89 \\
\hline 4 & 11,35 & 1,71 & 13,76 & 0,80 & 11,78 & 1,18 & 14,20 & 0,14 \\
\hline 5 & 11,77 & 1,18 & 13,82 & 1,13 & 12,34 & 0,99 & 14,57 & 0,72 \\
\hline 6 & 13,34 & 0,97 & 14,96 & 0,97 & 13,77 & 0,79 & 15,46 & 0,54 \\
\hline 7 & 15,31 & 0,17 & 16,35 & 0,48 & 15,45 & 0,07 & 16,08 & 0,62 \\
\hline 8 & 14,24 & 0,98 & 16,25 & 0,23 & 14,45 & 1,03 & 16,56 & 0,28 \\
\hline
\end{tabular}

Sex Female rho $=0,855 \mathrm{p}=0,000 \mathrm{n}=75$

Sex Male rho $=0,903 \mathrm{p}=0,000 \mathrm{n}=75$

rho (Correlation coefficient of Spearman among bone age (TW2) and stages of skeletal maturation.

Table 3. Arithmetic mean (X) and standard deviation (DE) of chronological age and bone age (TW2) by stages of skeletal maturation and sex.

Table 4 shows arithmetic mean and the standard deviation of the chronological age and the bone age (TW2) according to stages of maturation of the middle phalanx of the third finger and sex, it was found that in all the maturation stages the averages of the chronological age were smaller in the feminine sex than in the masculine one. In feminine sex the bone age overcame the chronological one in all the stages and in the masculine one in the stages $\mathrm{B}, \mathrm{C}$ and $E$. The stage $C$ (cap stage), it happened that 11,77 year-old chronological age and the bone one of 12,34 years, with a standard deviation of 1,18 and 0,99 years respectively in the females, while in the males, went to the 13,82 years and 14,57 years, with a standard deviation of 1,13 and 0,72 years respectively. It was observed that the females were earlier in their maturation stages than the males. The coefficient of correlation of ranges of Spearman among the bone age (TW2) and the stages of maturation of the middle phalanx of the third finger presented a value of 0,888 in the feminine sex and 0,921 in the masculine one, both sexes showed a positive correlation, very significant $(p<0,010)$.

\begin{tabular}{|c|c|c|c|c|c|c|c|c|}
\hline \multirow{2}{*}{$\begin{array}{l}\text { Stages of maturation of } \\
\text { the middle phalanx of } \\
\text { the third finger }\end{array}$} & \multicolumn{4}{|c|}{ Chronological age } & \multicolumn{4}{c|}{ Bone age (TW2) } \\
\cline { 2 - 10 } & \multicolumn{2}{|c|}{ Female } & \multicolumn{2}{|c|}{ Male } & \multicolumn{2}{c|}{ Female } & \multicolumn{2}{c|}{ Male } \\
\cline { 2 - 10 } & $\mathrm{X}_{1}$ & $\mathrm{DE}_{1}$ & $\mathrm{X}_{1}$ & $\mathrm{DE}_{1}$ & $\mathrm{X}_{2}$ & $\mathrm{DE}_{2}$ & $\mathrm{X}_{2}$ & $\mathrm{DE}_{2}$ \\
\hline $\mathrm{A}$ & 8,59 & 0,66 & 11,38 & 1,34 & 8,97 & 1,25 & 10,66 & 1,11 \\
\hline $\mathrm{B}$ & 11.55 & 1.4 & 13.06 & 0.71 & 11.52 & 0.92 & 13.25 & 0.92 \\
\hline $\mathrm{C}$ & 11,77 & 1,18 & 13,82 & 1,13 & 12,34 & 0,99 & 14,57 & 0,72 \\
\hline $\mathrm{D}$ & 13.83 & 1.23 & 15.93 & 0.86 & 13.59 & 1.17 & 15.7 & 0.63 \\
\hline $\mathrm{E}$ & 14.24 & 0.98 & 16.25 & 0.23 & 14.45 & 1.03 & 16.56 & 0.28 \\
\hline
\end{tabular}

Sex Female rho $=0,888 \mathrm{p}=0,000 \mathrm{n}=75$

Sex Male rho $=0,921 \mathrm{p}=0,000 \mathrm{n}=75$

rho (Correlation coefficient of Spearman among bone age (TW2) and stages of maturation of the middle phalanx of the third finger

Table 4. Arithmetic mean (X) and standard deviation (DE) of chronological age and bone age (TW2) by stages of maturation of the middle phalanx of the third finger and sex. 


\subsection{Identification of concordance between the studied methods}

Table 5 shows the percentages of females according to the stages of skeletal maturation and stages of maturation of the middle phalanx of the third finger, it was found that in the stage of skeletal maturation $1,100,00 \%$ was in the stage A of maturation of the middle phalanx of the third finger; in the stages 2,3 and $4,100 \%$ was in the stage B of the phalanx; in the stage $5,100 \%$ was in the C; in the 6 and the $7,100,00 \%$ was in the stage D and in the stage 8 , $100,00 \%$ was in the stage E of the phalanx. The coefficient of concordance Kappa between the stages of skeletal maturation and the stages of maturation of the middle phalanx of the third finger, presented a value of 1,000 that which evidenced a perfect concordance, very significant $(\mathrm{p}<0.010)$.

\begin{tabular}{|c|c|c|c|c|c|c|c|c|c|c|c|}
\hline \multirow{2}{*}{$\begin{array}{l}\text { Stages of } \\
\text { skeletal } \\
\text { maturation }\end{array}$} & \multirow{2}{*}{ Total } & \multicolumn{6}{|c|}{ Stages of maturation of the middle phalanx of the third finger } \\
\cline { 3 - 14 } & & \multicolumn{2}{|c|}{ A } & \multicolumn{2}{|c|}{ B } & \multicolumn{2}{|c|}{ C } & \multicolumn{2}{|c|}{ D } & \multicolumn{2}{|c|}{ E } \\
\cline { 2 - 14 } & & $\%$ & $\#$ & $\%$ & $\#$ & $\%$ & $\#$ & $\%$ & $\#$ & $\%$ \\
\hline 1 & 12 & 12 & 100,00 & - & - & - & - & - & - & - & - \\
\hline 2 & 8 & - & - & 8 & 100,00 & - & - & - & - & - & - \\
\hline 3 & 10 & - & - & 10 & 100,00 & - & - & - & - & - & - \\
\hline 4 & 4 & - & - & 4 & 100,00 & - & - & - & - & - & - \\
\hline 5 & 15 & - & - & - & - & 15 & 100,00 & - & - & - & - \\
\hline 6 & 6 & - & - & - & - & - & - & 6 & 100,00 & - & - \\
\hline 7 & 2 & - & - & - & - & - & - & 2 & 100,00 & - & - \\
\hline 8 & 18 & - & - & - & - & - & - & - & - & 18 & 100,00 \\
\hline
\end{tabular}

Coefficient Kappa $=1,000$ p $=0,000 \mathrm{n}=75$

Table 5. Percentage of females according to stages of skeletal maturation and stages of maturation of the middle phalanx of the third finger.

Table 6 shows the percentages of males according to the stages of skeletal maturation and stages of maturation of the middle phalanx of the third finger, it was found that in the stage of skeletal maturation 1, 100,00\% was in the stage A of maturation of the middle phalanx of the third finger; in the stages 2,3 and $4,100 \%$ was in the stage B of the phalanx; in the stage $5,100 \%$ was in the C; in the 6 the biggest percent was in the D $(75,00)$; in the $7,100,00 \%$ was in the stage D and in the stage $8,100,00 \%$ was in the stage $\mathrm{E}$ of the phalanx. The coefficient of concordance Kappa between the stages of skeletal maturation and the stages of maturation of the middle phalanx of the third finger, presented a value of 0,964 ; that which evidenced a high concordance, very significant $(p<0.010)$. 


\begin{tabular}{|c|c|c|c|c|c|c|c|c|c|c|c|}
\hline \multirow{3}{*}{$\begin{array}{l}\text { Stages of } \\
\text { skeletal } \\
\text { maturation }\end{array}$} & \multirow{3}{*}{ Total } & \multicolumn{10}{|c|}{ Stages of maturation of the middle phalanx of the third finger } \\
\hline & & \multicolumn{2}{|c|}{ A } & \multicolumn{2}{|c|}{ B } & \multicolumn{2}{|r|}{$\mathrm{C}$} & \multicolumn{2}{|c|}{$\mathrm{D}$} & \multicolumn{2}{|c|}{$\mathrm{E}$} \\
\hline & & \# & $\%$ & \# & $\%$ & \# & $\%$ & \# & $\%$ & \# & $\%$ \\
\hline 1 & 15 & 15 & 100,00 & - & - & - & - & - & - & - & - \\
\hline 2 & 11 & - & - & 11 & 100,00 & - & - & - & - & - & - \\
\hline 3 & 12 & - & - & 12 & 100,00 & - & - & - & - & - & - \\
\hline 4 & 2 & - & - & 2 & 100,00 & - & - & - & - & - & - \\
\hline 5 & 20 & - & - & - & - & 20 & 100,00 & - & - & - & - \\
\hline 6 & 8 & - & - & - & - & 2 & 25,00 & 6 & 75,00 & - & - \\
\hline 7 & 5 & - & - & - & - & - & - & 5 & 100,00 & - & - \\
\hline 8 & 2 & - & - & - & - & - & - & - & - & 2 & 100,00 \\
\hline
\end{tabular}

Coefficient Kappa $=0,964$ p $=0,000$ n=75

Table 6. Percentage of males according to stages of skeletal maturation and stages of maturation of the middle phalanx of the third finger.

\section{Discussion}

In this epigraph, one discussed the most important results and they were compared with the results of other investigations, with foundations starting from the revised bibliography.

With relationship to the variability intra and inter observant results were completely coincident in the three studied methods. The author considers that the results are due to the previous training of the investigators in each one of the studied evaluation methods.

With relationship to the variability intra observant and inter observant in the analysis of the stage of maturation of the middle phalanx of the third finger, coincidence existed among the four carried out observations. The author considers that the results are due to the simplification of this method, since in the same alone the changes are analyzed at level of a single phalanx.

In the studied sample, the bone age of the patients, calculated through the method TW2, didn't coincide with the chronological age. These results coincide with those of Malave and Rojas (Malavé \& Rojas, 2000) whom they outlined that, the chronological age is not a good indicator of the level of an individual's bone maturation.

In the three methods of study of the analyzed maturation, it was found that the females matured before the males of their same age. These results coincide with studies carried out for Grave and Townsend (Grave \& Townsend, 2003), Demirjian et al. (Demirjian et al, 1985) and Liversidge and Speechly (Liversidge \& Speechly, 2001), who they find that, the females mature more early than the males, that which is important to consider in the general evaluation of the orthodontist patient. 
There were a positive, very significant correlation $(\mathrm{p}<0,010)$ among the bone age (TW2) and the stages of skeletal maturation in both sexes ( $r h o=0,855$ for the females and rho $=0,903$ for the males). These results coincide with other carried out studies (Moore et al., 1990; Uysal et al., 2006).

In the analysis of the stages of maturation of the half phalange of the third finger it was found that the females were earlier in their maturation stages than the males. These results belong together with those obtained in other methods analyzed in this investigation and they coincide with those of Hägg and Taranger (Hägg \& Taranger, 1980a, 1980b, 1982) who they find that, the females mature early, that which is important to consider in the planning of the orthodontist treatment.

The coefficient of correlation of Spearman among the bone age (TW2) and the stages of maturation of the middle phalanx of the third finger showed positive, very significant correlations ( $p<0,010)$; in both sexes $(0,888$ in the feminine one and 0,921 in the masculine one). These results coincide with other studies that analyze the bone maturation through the development of the phalanges: Leite et al. (Leite et al., 1987) they carry out a longitudinal study, through which value the age skeletal analyzing the first one, second and third fingers of the hand, in a sample of 19 males radiographies and 20 females whose radiographic of the annual hand-wrist had taken from the 10 to the 16 years for the girls and of 12 to 18 years for the males and they find that although differences exist between the analysis of the total hand and that of the three fingers, the method of the three fingers never strays of that of the hand-wrist for more than 2.89 months for the males with a minimum deviation of 0.32 months and for the females, the maximum deviation was of 4.45 months with a minimum of 1.55 months. They also find that the maximum deviations happen during the time of coalition of the epiphysis with the diaphysis when the growth is coming closer to their finalization and consequently they are not of clinical importance. These authors conclude that the advantage of the use of the method of the three fingers is that they can incorporate in the lateral teleradiography, eliminating this way the necessity of other radiographies.

Shigemi Goto et al. (Shigemi Goto \& Yamada Miyazawa, 1996) carry out a study in which analyze the ossification of the distal phalanx of the first finger like an indicator of maturity for the initiation of the orthodontist treatment in 2 Japanese women with Class III malocclusion, where they conclude that the determination of the phases of maturation skeletal of the distal phalanx of the first finger, it can be a quick and useful clinical method, to evaluate the potential of residual growth in the cases of Class III.

Rossi et al. (Rossi et al., 1999) carry out a study in 72 feminine patients with ages understood between 8 and 13 years of age, where they analyze the proximal phalanx of the first finger and they find that in the patients that were in the epiphysis stage $C$, they were next to the peak of maximum speed of growth pubertal.

In relation of the concordance between the stages of skeletal maturation and the stages of maturation of the middle phalanx of the third finger, in the studied sample a high concordance existed, very significant $(p<0,010)$ in both sexes, being perfect in the feminine sex $(1,000)$. That which coincides with other carried out studies: Rajagopal and Sudhanshu (Rajagopal \& Sudhanshu, 2002) carry out a study with the objective of determining the dependability of using radiographic of the middle phalanx of the third finger as an indicator of skeletal maturation, in a sample of 75 girls and 75 children, between the 9 and 17 years of 
age; where they compare the stages of maturation of the cervical vertebras, and the stages of maturation of the middle phalanx of the third finger and they conclude that the assessment of the growth puberal based on the observations of the middle phalanx of the third finger observed by means of standard X-rays, is an useful method and it has as advantages: the smallest exhibition to the $X$ rays and that $X$ rays supplementary machine is not needed.

Madhu et al. (Madhu et al., 2003) carry out a study with the objective of obtaining a unique and simple method to determine the skeletal maturation using the stages of development of the middle phalanx of the third finger that one observes in a radiographic, taken with a conventional $X$ ray dental machine; in a sample of 67 patients, 35 males between 10 and 18 years of age and 32 females between 8 and 16 years. To the patients they carry out them lateral teleradiographies of skull and an X-ray of the area of the middle phalanx of the third finger, where they determine the stages of maturation of the cervical vertebras of the patients in previous stages to the peak puberal, patient that were in the peak of growth puberal and patient in those that it had already happened the peak of growth puberal and the stages of the middle phalanx of the third finger are classified in 3 stages: patient in the previous period to reach the peak pubertal of growth, patient that are in the period of growth pubertal and those patients that the period of growth pubertal had passed. These authors find agreement among the results obtained in the analysis of the cervical vertebras and of the middle phalanx of the third finger and they conclude that the analysis of the maturation of the middle phalanx of the third finger, is an alternative method that can be used to determine the skeletal maturation of the children in growth.

Ozer et al. (Ozer et al., 2006) carry out a study in 150 masculine patients, with ages understood among 9 and 19 years that were in orthodontist treatment, with the purpose of determining the correlation between the index of maturation of the cervical vertebras and the stages of maturation of the middle phalanx of the third finger, for that which they carry out lateral teleradiography of skull and X-rays of the middle phalanx of the third finger of the left hand, finding high correlation coefficients between the stages of vertebral maturation and those of the phalanges. They conclude that the middle phalanx of the third finger can be used in the evaluation of the skeletal maturation of the patients.

From the clinical point of view in the planning of an orthodontist treatment, we should consider if the patient has begun the spurt of pubertal growth, if this is happening in that moment or if it has concluded (Tedaldi, 2007). With the analysis of the stages of maturation of the middle phalanx of the third finger, visualized in an X-ray of $41 \times 31 \mathrm{~mm}$., is possible to determine: if the patient has not reached the spurt of pubertal growth (Stage A), if it is next or this event already began (B), if it is in its maximum peak (C) or if it is in the descending curve of growth pubertal (D and E) (Toledo Mayarí \& Otaño Lugo, 2010).

Due to the high correlation coefficient found in this sample, between the stages of maturation of the middle phalanx of the third finger and the bone age in both sexes, as well as to the high concordance found in this study, among the evaluation of the maturation through the left hand and the analysis of the middle phalanx of the third finger, which was perfect in the feminine sex, and considering the current tendency in Orthodontics of reducing the number of radiations, we propose inside the diagnosis for the evaluation of the potential growth of the patients, the realization of an X-ray of $41 \times 31 \mathrm{~mm}$. of the middle phalanx of the third finger of the left hand (Fig. 3), with the following requirements: 
An auxiliary table will be used, where the radiography of $41 \times 31 \mathrm{~mm}$. will be placed, with the vertical bigger axis coinciding with the same position of the phalanx and with the active face in front of the focus. The radiograph will be located on the union between the middle and proximal phalanx of the third finger of the left hand, with the coincident located reference point with the proximal phalanx. The focus will be centered in perpendicular sense to the table, with an angle of $90^{\circ}$, at a distance focus film, using short cone, of $11 \mathrm{~cm}$. with a time of exhibition of 0,5 second. The calibration of the machine will be of 110 volt / 10 MA / seg. They will take all the measures of protection radiological established (Ugarte et al., 2004) and a dental machine of $X$ rays and dental films standard of $41 \times 31 \mathrm{~mm}$., Kodak marks. The one revealed will be executed looking for soft revealed low contrasts.

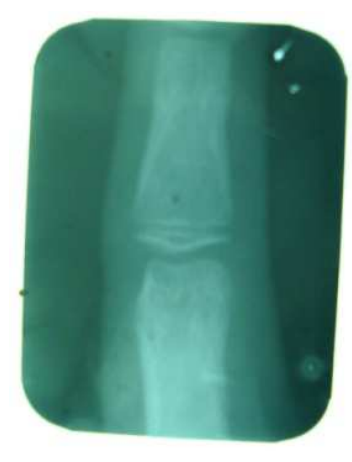

Fig. 3. Radiographic of middle phalanx of the third finger.

The author considers that, in the patients, it is not necessary to carry out a lateral teleradiography of skull, the evaluation of the potential of growth, inside the diagnosis in Orthodontics, one can make through the stages of maturation of the middle phalanx of the third finger of the left hand, which contributes the following benefits:

It constitutes a simplified method that can be applied in any service of Orthodontics and it allows planning for the treatment of orthodontics in dependence of the potential of growth which the patient presents that makes more efficient therapy.

It allows bigger efficiency and decrease of the costs and it can be carried out in the dental $\mathrm{X}$ rays machine, for what includes relative savings to the depreciation of the machine of X-rays and the energy consumption.

They diminish the quantity from radiations to those that are exposed to the patients and the auxiliary personnel (technicians in radiology), as well as, the radiations in the local where the radiographies were taken.

\section{Conclusions}

The evaluation of the potential of growth that the patients of Orthodontics present can be made by means of the realization of radiography of the middle phalanx of the third finger of the left hand.

In the three certain methods, it was found that the females mature before the males of their same age. 
It existed a high correlation and concordance among the studied methods of determination of the potential growth.

The substitution of the radiography of the left hand, for the radiography of the middle phalanx of the third finger, allows the realization of that in the own service of Dentistry, with the benefits that it reports as for the patient's better attention.

The results of this study prove the hypothesis formulated and constituted part of the Thesis in option to PhD degree in Dentistry of the author.

\section{Acknowledgment}

This research project would not have been possible without the support of many people. The author wishes to express her gratitude to her mother Dr. Zoila Gúdula Mayarí Cano, who introduced her into Dentistry, her tutor, Prof. PhD. Rigoberto Otaño Lugo of blessed memory who was abundantly helpful and offered invaluable assistance, support and guidance. Deepest gratitude also goes to all the members of the investigation team, without whose knowledge and assistance this study would not have been successful.

\section{References}

Abreu Suárez, G., González Valdés, J A., Jordán Rodríguez, J. \& Chiong Molina, D. (1995). Growth and bone maturation in asthmatic children. Rev Cub Aliment Nutr, Vol.9, No.2, pp. 106-12.

Bayarre, H. et al. (2005). Descriptive Statistic and statistic of Health, Editorial Medical Sciences, Havana City, Cuba

Begole, EA. (2003). Statistic for the orthodontist, In: Orthodontics. General and Technical principles, Graber TM, Vanarsdall (h) RL, 3a ed., Pan-American Medical editorial, Buenos Aires, Argentina.

Björk, A. \& Helm, S. (1967). Prediction of age of maximum puberal growth in body height. Angle Orthod, Vol.37, No.2, pp. $134-43$.

Bujaldón Daza, JM., Rodríguez Argáiz. R. \& Bujaldón Daza, AL. (1998). Study preliminary about the validity of the index of maturation of the cervical vertebras as diagnostic tool in the orthodontist planning, RCOE, Vol.3, No.8, pp 751-760.

Cannut Brusola, JA. (1988). Clinical orthodontics, Scientific and Technical editions, S.A., Barcelona, España.

Cattani, A. (2003). Studies Health and the adolescent's development. Module I: Lesson 1. Growth and development puberal during the adolescence, [on-line article], 11.05.2005.Available from: http://escuela.med.puc.cl/paginas/OPS/Curso/Lecciones/Leccion01/M1L1Leccio n.html.

Ceglia, A. (2005). Indicative of maturation of the bone, dental and morphological age. Revista Latinoamericana de Ortodoncia y Odontopediatría. [online], 03.02.2007; Available from: http://www.ortodoncia.ws/publicaciones/2005/indicadores_maduracion_edad_o sea_dental_morfologica.asp .

Cha, KS. (2003). Skeletal changes of maxillary protraction in patients exhibiting skeletal class III malocclusion: a comparison of three skeletal maturation groups. Angle Orthod, Vol.73, No.1, pp. 2635. 
Demirjian, A., Bushchang, PH., Tanguay, R. \& Patterson, DK. (1985). Interrelationships of measure of somatic, skeletal dental and sexual maturity. Am J Orthod Dentofac Orthop, Vol.88, pp. 433- 8.

Edilmar, M., Tavano, O., \& Carvalho, IM. (2005). Cervical vertebral like estimate do grow and development in patient with lip-palatal fissures. Salusvita Vol.24, No.1, pp. 11-28.

Fiani, E. (1998). Indicative of maturation skeletal, bone, dental and morphological age. Rev Cub Ortod, Vol.13, No.2, pp. 121 - 125.

Fishman, LS. (1982). Radiographic evaluation of skeletal maturation. A clinically oriented method based on hand-wrist films. Angle Orthod, Vol.52, pp. 88-111.

Freitas, D., Maia, J., Beunen, G., Lefevre, J., Claessens, A., Marques, A. et al. (2004). Skeletal maturity and socio-economic status in Portuguese children and youths: the Madeira growth study. Ann Hum Biol, Vol.31, No.4, pp. 408-20.

Gandini, P., Mancini, M. \& Andreani, F.(2006). A comparison of hand-wrist bone and cervical vertebral analyses in measuring skeletal maturation. Angle Orthod, Vol.76, No.6, pp. 984-9.

Geran, RG., McNamara, JJr., Baccetti, T., Franchi, L. \& Shapiro, L. (2006). A prospective longterm study on the effects of rapid maxillary expansion in the early mixed dentition. Am J Orthod Dentofac Orthop, Vol.129, No.5, pp. 454-62.

Grave, K. \& Townsend, G. (2003). Cervical vertebral maturation as a predictor of the adolescent growth spurt. Aust Orthod J, Vol.19, No.2, pp. 44-47.

Greulich, WW. \& Pyle, SI. (1959). Radiographic Atlas of Skeletal Development of the Hand and Wrist. 2nd ed., Oxford University Press, London, England.

Gupta, S. (1995). Assessment of puberty growth spurt in boys and girls: a dental radiographic method. J Indian Soc Pedod Prev Dent, Vol.13, No.1, pp.4 - 9.

Gutiérrez Muñiz, JA., Berdasco Gómez, A., Esquivel Lauzurique, M., Jiménez Hernández, JM., Posada Lima, E., Romero del Sol, JM. et al. (2006). Growth and Development. In: Pediatrics, Collective of Authors, T1. [online]. 14.02.2007. Editorial Medical Sciences; Havana, Cuba. Available from: http://www.bvs.sld.cu/libros_texto/pediatria_tomoi/parteii_cap06.pdf.

Hägg, U. \& Taranger, J. (1982). Maturation indicators and the pubertal growth spurt. Am J Orthod Dentofac Orthop, Vol.82, No.4, pp. 299 - 309.

Hägg, U. \& Taranger, J. (1980). Menarche and voice change as indicators of the pubertal growth spurt. Acta Odontol Scand, Vol.38, pp. $170-86$.

Hägg, U. \& Taranger, J. (1980). Skeletal stages of the hand and wrist as indicators of the pubertal growth spurt. Acta Odontol Scand, Vol.38, pp. 187 - 200.

Hassel, B. \& Farman, AG. (1995). Skeletal maturation evaluation using cervical vertebrae. Am J Orthod Dentofac Orthop, Vol.107, pp. 58-66.

Izaguirre de Espinoza, I., Macías de Tomei, C., Castañeda de Gómez, M. \&, Méndez Castellano H. (2003). Atlas Venezuelan bone maturation. An Venez Nutr, Vol.16, No.1, pp. 23-30.

Jiménez Hernández, JM., Romero del Sol, JM., Rubén Quesada, M., Barrera Yanes, R, Berdasco Gómez, A. \&, Jordán Rodríguez, J. (1986). Study of bone maturation by sex and race. Rev Cub Ped, Vol.58, No.5, pp. 533-45.

Jiménez, JM., Romero, JM., Barrera, R., Rúben, M., Berdasco, A. \& Jordán, J. (1987). Patron of Cuban population's bone maturation. ISCMH, Havana City, Cuba. 
Jordán, RJ. (1979). Human Development, Editorial Scientific-technique, Havana, Cuba.

Jordán J., Berdasco, A., \& J iménez, JM. (1987). Bone maturation. Method TW2, ISCMH, Havana City, Cuba

Leite, HR., O'Reilly, MT. \& Close, J. (1987). Skeletal age assessment with first, second and third fingers. Am J Orthod Dentofac Orthop; Vol.92, pp 492-8.

Liversidge, HM. \& Speechly, T. (2001). Growth of permanent mandibular teeth of British children aged 4 to 9 years. Ann Hum Biol, Vol.28, No.3, pp. 256-62.

Madhu, S., Hedge, AM. \& Munshi, AK. (2003). The developmental stages of the middle phalanx of the third finger (MP3): a sole indicator in assessing the skeletal maturity? J Clin Pediatr Dent, Vol.27, No.2, pp.149-56.

Malavé, Y. \& Rojas, I. (2000). Análisis Carpal como Indicador de Maduración Ósea. Acta Odontol Venez [online] 2000, Vol.38, No.3, pp.4-9. Available from

http:/ / www2.scielo.org.ve/scielo.php?script=sci_arttext\&pid=S000163652000000300002\&lng=en\&nrm=iso .

Mayoral, J. \& Mayoral, G. (1990). Orthodontics: Fundamental principles and practice. 6a ed., Labor S.A., Barcelona, Spain.

Moore, RN., Moyer, BA. \& DuBois, LM. (1990). Skeletal maturation and craniofacial growth. Am J Orthod Dentofac Orthop, Vol.98, pp.33-40.

Nanda, R. (1955). The rate of growth of several facial components measured from serial cefalometric roentgenograms. Am J Orthod Dentofac Orthop, Vol.41, pp.129-141.

Ortega, AI., Haiter-Neto, F., Bovi Ambrosano, GM., Bóscolo, FN., Almeida, SM. \&, Spinelli Casanova, M. (2006). Comparison of TW2 and TW3 skeletal age differences in a Brazilian population. J Appl Oral Sci. [online]. 27.09.2007. Vol.14, No.2, Available from:

http:/ / www.scielo.br/scielo.php?script=sci_arttext\&pid=S167877572006000200014 .

Ortiz, M., Godoy, S., Fuenmayor, D., Farias, M., Quirós, O., Rondón, S. \& Harry, L. (2007). Method of bone maturation of the cervical vertebras, in patient of the Graduate of Orthodontics Interceptiva, UGMA-2006. Revista Latinoamericana de Ortodoncia y Odontopediatría [online]. 29.06.2007. Available from:

http://www.ortodoncia.ws/publicaciones/2007/maduracion_osea_vertebras_cer vicales.asp .

Ozer, T., Kama, JD. \&, Ozer, SY. (2006). A practical method for determining pubertal growth spurt. Am J Orthod Dentofac Orthop, Vol.130, No. 2, pp. 131-6.

Padrós, E. \& Creus, M. (2002). Revision of the methods to study the growth craniofacial in orthodontics. Ortod Clínic, Vol.5, No. 2, pp. 100-116.

Paesano, PL., Vigone, MC., Siragusa, V., Chiumello, G., DelMaschio, A. \& Mora, S (1998). Assessment of skeletal maturation in infants: comparison between two methods in hypothyroid patients. Pediatr Radiol, Vol.28, pp. 622-26.

Pancherz H. \& Hägg V. (1985). Dentofacial orthopedic in relation to somatic maturation: An analysis of 7 consecutive cases treated with the Herbst appliance. Am J Orthod Dentofac Orthop, Vol.88, pp. 273 - 87.

Peluffo, PL. (2001). Indicators of maturation. Bone age and cervical vertebrae. Rev Odont Interdis, Vol.11, No. 3, pp. 9-15.

Proffit, WR. (1994). Orthodontics: Theory and practice. 2a ed., Mosby- Doyma Libros, S. A., Madrid, Spain. 
Quirós Álvarez, OJ. (2006). Base Bio mechans and Clinical Applications on Interceptive Orthodontics. Actualidades Médico Odontológicas Latinoamericanas, Caracas, Venezuela.

Quirós Álvarez, OJ. (2000). Manual of Maxillary Functional Orthopedics and Interceptive Orthodontics. Actualidades Médico Odontológicas Latinoamericanas, Caracas, Venezuela.

Rajagopal, R. \& Sudhanshu, K. A. (2002). Comparison of modified MP3 stages and the cervical vertebrae as growth indicators. J Clin Orthod, Vol.7, pp. 398-406.

Rakosi, T. \& Jonas, I. (1992). Atlas of Maxillary Orthopedics. Diagnostic. Scientific and Technical editions, S. A., Barcelona, Spain.

Recalde Cortes, C., López Santomauro, D. \& Palleiro, AM. (1997). Hand radiography, their clinical value. CEDDU, Vol. VIII, No.1, pp. 51-67.

Rossi Rowdley, R., Sandro Gomes, A. \& Pacheco Thomé, MC. (1999). Correlation among dental stages mineralization and estimative of skeletal maturation. Ortodontia, Vol. 32, No. 3, pp. 48-58.

San Roman, P., Palma, JC., Oteo, MD. \& Nevado, E. (2002). Squeletal maturation determined by cervical vertebrae development. Eur J Orthod, Vol.24, pp. 303-11.

Shigemi Goto, A. \& Yamada Miyazawa, N. (1996) Ossification of the distal phalanx of the first digit as a maturity indicator for initiation of orthodontic treatment of Class III malocclusion in Japanese women. Am J Orthod Dentofac Orthop, Vol.110, pp. 490-501.

Spinelli Casanova, M., Ortega, AI., Haiter-Neto, F. \& de Almeida, SM. (2006). Comparative Analyze bone maturation by Grave-Brown's method among conventional images and digitized. Dental J Press Orthodon Facial Orthop [online]. 22.06.2007, Vol. 11, No. 5, pp. 104-109. Available from: http://www.scielo.br/pdf/dpress/v11n5/a11v11n5.pdf .

Tanner, JM., Whitehouse, RH., Cameron, N., Marshall, WA., Healy, MJR., \& Goldstein, H. (1983). Assessment of skeletal maturity and prediction of adult height (TW2 method). 2nd ed.. Academic Press, London, England.

Tedaldi, J., Calderón, R., Mayora, L., Quirós, O., Farias, M., Rondón, S., et al. (2007). Maloclussions treatment according to the stage of maturation carpal. Bibliographical revision. Revista Latinoamericana de Ortodoncia y Odontopediatría. [online], 29.06.2007; Available from: http://www.ortodoncia.ws/publicaciones/2007/tratamiento_maloclusiones.asp.

Toledo Mayarí, G. \& Otaño Lugo, R. (2010). A simplified method to determine the potential growth in Orthodontics patients. Rev Cubana Estomatol, Vol.47, No.2, pp. 134142.[online]. 23.09.2011. Available from: http://scielo.sld.cu/pdf/est/v47n2/est02210.pdf .

Toledo Mayarí, G. \& Otaño Lugo, R. (2010). Concordance among skeletal maturation stages and dental calcification stages. Rev Cubana Estomatol, Vol.47, No.2, pp. 207-214. [online]. 23.09.2011. Available from: http:/ / scielo.sld.cu/pdf/est/v47n2/est09210.pdf

Toledo Mayarí, G. \& Otaño Lugo, R. (2010). Assessment of bone maturation in cervical vertebrae in Orthodontics patients. Rev Cubana Estomatol, Vol.47, No.3, pp. 326-335. [online]. 23.09.2011. Available from: http://scielo.sld.cu/pdf/est/v47n3/est06310.pdf 
Toledo, V. (2004). Orthognatic Surgeon Simplification of the treatment Surgical Orthodontic in Adults., Amorca Caracas, Venezuela.

Ugarte Suárez, JC., Banasco Domínguez, J. \& Ugarte Moreno, D. (2004). Manual of Imagenology. 2a ed., Editorial Medical Sciences, Havana City, Cuba.

Uysal, T., Ramoglu, IF., Basciftci, FA. \& Sari, ZA. (2006). Chronologic age and skeletal maturation of the cervical vertebrae and hand-wrist: is there a relationship? J Orthod Dentofac Orthop, Vol.130, No.5, pp. 622-8. 


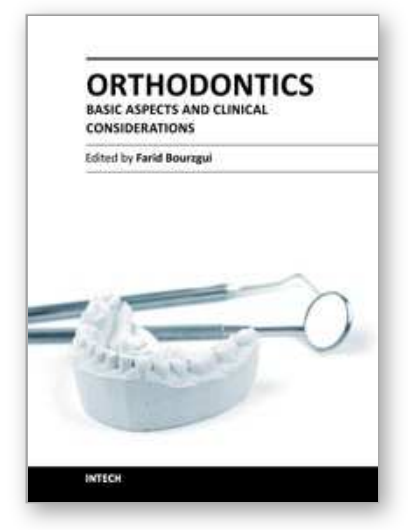

\author{
Orthodontics - Basic Aspects and Clinical Considerations \\ Edited by Prof. Farid Bourzgui
}

ISBN 978-953-51-0143-7

Hard cover, 446 pages

Publisher InTech

Published online 09, March, 2012

Published in print edition March, 2012

The book reflects the ideas of nineteen academic and research experts from different countries. The different sections of this book deal with epidemiological and preventive concepts, a demystification of cranio-mandibular dysfunction, clinical considerations and risk assessment of orthodontic treatment. It provides an overview of the state-of-the-art, outlines the experts' knowledge and their efforts to provide readers with quality content explaining new directions and emerging trends in Orthodontics. The book should be of great value to both orthodontic practitioners and to students in orthodontics, who will find learning resources in connection with their fields of study. This will help them acquire valid knowledge and excellent clinical skills.

\title{
How to reference
}

In order to correctly reference this scholarly work, feel free to copy and paste the following:

Gladia Toledo Mayarí (2012). A Simplified Method to Determine the Potential Growth in Orthodontics Patients, Orthodontics - Basic Aspects and Clinical Considerations, Prof. Farid Bourzgui (Ed.), ISBN: 978-953-51-01437, InTech, Available from: http://www.intechopen.com/books/orthodontics-basic-aspects-and-clinicalconsiderations/a-simplified-method-to-determine-the-potential-growth-in-orthodontics-patients-

\section{INTECH}

open science | open minds

\section{InTech Europe}

University Campus STeP Ri Slavka Krautzeka 83/A 51000 Rijeka, Croatia Phone: +385 (51) 770447

Fax: +385 (51) 686166 www.intechopen.com

\section{InTech China}

Unit 405, Office Block, Hotel Equatorial Shanghai No.65, Yan An Road (West), Shanghai, 200040, China 中国上海市延安西路65号上海国际贵都大饭店办公楼405单元 Phone: +86-21-62489820

Fax: $+86-21-62489821$ 
(C) 2012 The Author(s). Licensee IntechOpen. This is an open access article distributed under the terms of the Creative Commons Attribution 3.0 License, which permits unrestricted use, distribution, and reproduction in any medium, provided the original work is properly cited. 